\title{
Heterogeneity of preferences for the benefits of Environmental Stewardship: A latent-class approach
}

\author{
Guy Garrod ${ }^{a}$, Eric Ruto ${ }^{\mathrm{a}, 1}$, Ken Willis ${ }^{\mathrm{b}}$, Neil Powe ${ }^{\mathrm{b}}$ \\ ${ }^{a}$ Centre for Rural Economy, School of Agriculture, Food and Rural Development, \\ Newcastle University, Newcastle upon Tyne, NE1 7RU, UK \\ ${ }^{\mathrm{b}}$ Centre for Research in Environmental Appraisal and Management, School of \\ Architecture, Planning and Landscape, Newcastle University, Newcastle upon Tyne, \\ NE1 7RU, UK
}

\begin{abstract}
Since 2005, Environmental Stewardship (ES) has been the principal agri-environment scheme for England and is the key instrument for the delivery of increased environmental benefits from agricultural landscapes. The main objective of this study is to investigate whether or not individuals' preferences for the environmental benefits associated with ES vary depending on types of landscapes within which these benefits are delivered. A latent class model is applied to data obtained from a choice experiment survey of over 1,000 respondents sampled across England. The results suggest that individuals have heterogenous preferences for the benefits of ES, though different segments of the population with more homogenous preferences can be identified. In particular, higher levels of benefit are often associated with the operation of ES in landscapes close to where respondents live. This leads to the suggestion that, in order to maximise the benefits of ES, its implementation could take this result into account by encouraging greater uptake from farmers whose land is closer to large populations.
\end{abstract}

Keywords: Agri-environment; Environmental Stewardship; Landscape preferences; choice experiment; latent class model; United Kingdom

\footnotetext{
${ }^{1}$ Corresponding author. Tel.: +44 1912223593; fax: +44 1912225411.
}

E-mail address: Eric.Ruto@ncl.ac.uk (E. Ruto). 


\section{Introduction}

Environmental Stewardship (ES) was launched in 2005 as the new agri-environment scheme for England and aims to cover 70\% of its land area by 2013 (Defra and Natural England, 2008). The main focus of the scheme is on biodiversity conservation and resource protection, along with the enhancement of landscape quality and character (Natural England, 2011a). ES has two main strands: Entry Level Stewardship (ELS) which aims to deliver relatively basic environmental improvements across the majority of farmland in England; and Higher Level Stewardship (HLS) a competitive scheme that targets 110 areas to maximise environmental benefits (Natural England, 2011a). While other studies have investigated the contribution that ES has made to environmental management (e.g. Davey et al., 2010; Ewald et al., 2010; Field et al., 2011), this paper examines public preferences for the environmental benefits of ES and specifically investigates whether or not these preferences vary across landscape types.

In recent years a growing number of studies have used economic techniques, such as choice experiments and contingent valuation, to value the environmental benefits associated with changes to the management of agricultural landscapes (e.g. Willis et al., 1995; Pruckner, 1995; Gonzalez and Leon, 2003; Campbell, 2007; Hanley et al., 2007; Hynes et al., 2011). This study does not estimate a value for the environmental benefits provided by ES, but instead uses a choice experiment approach to test the hypothesis that the benefits that the general public gain from ES do not vary across the different landscapes over which it is applied. The alternative to this would be that the public have different preferences for the benefits of ES in different landscape contexts. If this were indeed the case, it would be consistent with the findings of other studies that show preference heterogeneity for environmental goods or for landscape, some of which demonstrate that public preferences may be linked to geographic location (e.g. Purcell et al., 1994; Hunziker, 1995; Dramstad et al., 2006; Brouwer et al., 2010; Lokocz et al., 2011) or to personal characteristics (e.g. Kearney et al., 2008; Park et al., 2008; Hanley et al., 2009).

Some studies (e.g. Kleijn et al.; Davey et al., 2010) suggest that agri-environment schemes may not deliver the same environmental benefits across all landscapes in which they are implemented. If the economic value of the non-market benefits associated with agri-environment schemes can be shown to vary spatially, then this suggests that, rather than using aggregate data to inform the design of such schemes, a better approach may be to use spatially disaggregated data on their likely costs and benefits. The linkage of economic benefits as measured by valuation studies to environmental outcomes is investigated further in the studies making up the UK National Ecosystems Assessment, a systematic attempt to provide a comprehensive evaluation of the UK's natural environment in terms of the benefits it provides to society (see Bateman et al., 2011).

As a first step towards understanding how the non-market benefits of ES may vary spatially, this study investigated the hypothesis that people's preferences for the scheme differ according to the landscape context. For example, people's preferences for ES may be correlated with their preferences for landscape characteristics or for the ecosystem services and biodiversity characteristically delivered in these landscapes. 
Currently, spatial differences are accounted for in the design of ES by linking scheme prescriptions to one of Natural England's National Character Areas (NCAs) (Quillerou et al., 2011). There are 159 NCAs in England each with a distinctive landscape character and ecology and requiring tailored management strategies if the biodiversity and ecosystems services they contain are to be maintained and enhanced (Natural England, 2011b).

This study uses a landscape typology based on NCAs to investigate whether or not the non-market benefits associated with ES depend upon the landscape contexts within which they are delivered. This exercise was based on a large survey of the general public across England that used choice experiments to investigate relative preferences for the benefits of ES across different landscape types. The resulting data were modelled using a latent class approach that accounts for the heterogeneity of preferences and allows for the identification of groups or segments within the population that share similar preferences for the location of ES benefits.

\section{Methods}

\subsection{Choice Experiment Design}

This study used a choice experiment (CE) approach to investigate how the nonmarket benefits of ES varied across different landscapes. Investigating how benefits varied across all 159 NCAs within a CE framework was not feasible, so the first objective of this research was to adopt a landscape typology based on a smaller number of landscape types.

The typology used was based on the earlier work of Swanwick et al. (2007), who clustered NCAs into landscape categories that would be suitable for agricultural landscape valuation. Their typology allocated Joint Character Areas (JCAs) (the precursors to NCAs) to six categories which covered the majority of the country. Following detailed investigation (see Boatman et al., 2010 for more details) it was decided that this study would use a revised version of the Swanwick classification, but that the two upland categories in the original classification would be merged to generate five distinctive landscape categories.

While this relatively small set of landscape classes will not account for the full diversity and complexity of landscapes, its use in this study represents a significant advance on approaches that do not take any account of the potential for the nonmarket benefits of environmental management to vary depending on the landscape context within which they are delivered. Furthermore, as this approach uses an existing national landscape classification, based on objective data, it is relatively straightforward to describe the characteristics and map the distribution of the five landscape types. Appendix 1 provides the written descriptions of the five landscape types provided to respondents in the questionnaire survey, while Appendix 2 maps their distribution. In addition to this summary material, carefully chosen photographs were used to illustrate the current state of each landscape type, avoiding the need for the more complex landscape visualisation techniques required when evaluating future landscapes (e.g. Willis and Garrod, 1992; Bishop and Hull, 1991; Daniel and Meitner, 2001; Karjalainen and Tyrvainen 2002; Meitner, 2004). 
A total of 18 pages of illustrated factsheets were devised in conjunction with scientists from Defra and Natural England to provide information to respondents about ES and the environmental management that farmers had to undertake when joining the scheme. Additional material described the impact that both ELS and HLS management would be expected to have by 2013 if both elements achieved their target levels of uptake by farmers. Scheme impacts were valued in relation to a counterfactual, that is the likely situation in the absence of the scheme (in terms of land management activity) for the different landscape types. After consultation with Defra the counterfactual was based on forward projections of current agricultural policy (without ES) to 2013 (see Boatman et al., 2010 for more details).

The CE approach has increasingly been used to value the effects of changes in environmental attributes or policies (e.g. Adamowicz et al., 1998; Ruto and Garrod, 2009; Espinosa-Goded et al., 2010). Compared to the contingent valuation approach (Mitcell and Garson, 1989), CEs are particularly well suited to measuring the marginal value of the attributes of a good or policy. In this study a CE was used to evaluate the relative preferences that the general public have for the benefits of ES across the different landscape types.

The multinomial logit (MNL) model (McFadden, 1974) is the most commonly used discrete choice model for the analysis of results from CEs. While the relative simplicity of the MNL model is a clear advantage, it has some important limitations. For example, the MNL framework imposes homogenous preferences across respondents and its concomitant assumption of the independence of irrelevant alternatives (IIA) (Hausman and McFadden, 1984). Preferences, however, may be heterogeneous and accounting for the presence of heterogeneity enables computations of unbiased estimates of individual preferences. In addition, accounting for preference heterogeneity provides a broader picture of the distributional consequences and other impacts of policy actions and provides better insight on policy outcomes.

Among the recent innovations aimed at accounting for preference heterogeneity in choice models are the mixed logit models (McFadden and Train, 2000; Train, 2003) of which the latent class model is a special case (Wedel and Kamakura, 2000). The mixed logit model accounts for preference heterogeneity by allowing utility parameters to vary randomly (and continuously) over individuals. The latent class model, on the other hand, postulates a discrete distribution of tastes in which individuals are intrinsically sorted into a number segments (classes), each characterised by homogenous segments though heterogeneous across segments (Boxall and Adamowicz, 2002). The segmentation derived from the LCM can be of particular interest to policy makers as it can be used to identify and investigate groups of people with particular preferences.

Latent class models (LCMs) have been applied in market research (for a review, see Wedel and Kamakura, 2000), and more recently they have been used in recreational demand studies (e.g. Scarpa and Thiene, 2005) and stated preference applications (e.g. Boxall and Adamowicz, 2002; Garrod et. al., 2002; Greene and Hensher, 2003; Birol et al., 2006; Ruto et. al., 2008; Ruto and Garrod, 2009; Glenk, 2011) including public preferences for landscape (e.g. Morey et al., 2008; Sevenant and Antrop, 2010). Brouwer et al. (2010) used LCM and other approaches to assess preference 
heterogeneity related to the spatial distribution of water quality improvements in a river basin and found that respondents valued water quality improvements differently depending on where they lived.

\subsection{Implementation}

The questionnaire survey was extensively piloted and pre-tested in a process that included six focus groups, twelve verbal protocol interviews and a pilot survey of 103 individuals in nine locations across England (see Boatman et al., 2010 for an extensive description of this process). Among other things, this exercise was used to confirm that respondents could assimilate and interpret the high volume of mainly visual information (with supporting text) required to describe the five landscape types, the operation and predicted environmental outcomes of ES, and the expected impacts that different levels of environmental management (i.e. under ELS and HLS) would have across landscape types. The pre-testing also confirmed that respondents could understand and respond to the hypothetical scenario underlying the CE, which stated that ES would only operate in some but not all of the five landscapes identified in the questionnaire. Respondents were told that the purpose of the exercise was to discover within which landscapes ES would provide them with most benefits. They were reassured that this scenario was only hypothetical and that there was no intention of the scheme not operating in all landscapes as it does currently.

The choice cards used in the survey were designed to explore whether or not respondents' utilities for the non-market benefits of ES varied across the different landscape types. Rather than portraying broad changes to each landscape type, the information provided to respondents provided information on the expected changes that target uptake of scheme options would have on specific habitats and features such as species rich grassland, wetland, woodland, field boundaries, field margins, ditches and stubble that would be present in the different landscapes in different quantities and qualities.

Choice profiles were derived using five attributes, each with two levels (denoting the presence or absence of ES benefits in one of the five landscape categories). An orthogonal fractional factorial design provided distinct eight choice profiles. A set of 28 distinct pairs could be derived from these eight profiles and these paired profiles were used to form the choice cards (see Figure 1 for an example). To limit the cognitive burden, respondents were only required to select their most preferred alternative for each of a sequence of four choice cards, which were selected randomly (without replacement) from the set of 28.

As this exercise was only concerned in deriving relative utilities for ES benefits across the five landscape types, there was no need to incorporate a price attribute in the choice alternatives. This omission of a price term is not unique. In their investigation of preferences for landscape preservation, Morey et al. (2008) use only attitudinal data to derive latent class membership to help explain variation in WTP elicited from an earlier CV question. A utility scale, without a price attribute, was also employed by Sayadi et al. (2005) to assess preferences for agri-environmental attributes in the Alpurjarran landscape of south-eastern Spain. 
Figure 1: Example of choice cards

CHOICE 2: CHOOSE OPTION A OR B

\begin{tabular}{|c|c|}
\hline & OPTION A \\
\hline LANDSCAPE 1 & OPTION B \\
\hline CHALK \& \\
LIMESTONE MIXED \\
\hline LANDSCAPE 2 \\
EASTERN \\
ARABLE \\
\hline LANDSCAPE 3 \\
\hline SOUTH EAST MIXED \\
(WOODED) \\
\hline UPLAND FRINGE \\
\hline LANDSCAPE 4 \\
\hline
\end{tabular}


Choice of alternative was modelled as a function of the attributes of the various alternatives offered (i.e. the provision of ES benefits in the five different landscapes). Analysing respondent choice across a large number of these choice sets permitted the estimation of both the trade-off that respondents are willing to make between ES in different landscapes and the relative preferences of respondents for ES in each landscape type. The analysis of choices allowed the marginal utility of the ES in the different landscape types to be estimated.

This study was based on a stratified random sample of households across England. The sampling strategy adopted obtained a representative mix of respondents from both urban and rural areas in England and was also designed to ensure that a nationally and geographically representative proportions of respondents (in terms of age, education and socio-economic class) was drawn from each of five landscape areas. In order to minimise survey costs, the sample was stratified by areas, and a number of randomly selected households were sampled in each area. The sample reflected the distribution of household numbers in the different landscape areas: chalk and limestone mixed (10.8\% of households); eastern arable (16.8\%); south east mixed (25.2\%); upland and upland fringe (16.9\%); and western mixed (30.3\%). Some postcodes (usually coastal postcodes) and hence some households $(6.01 \%)$ could not be assigned to the landscape areas on the basis of the digitised landscape boundaries provided. The sample was also stratified using Defra's Rural and Urban Area Classification (Defra 2007) at the Office of National Statistics Output Area (OA) level. This ensured that the sample had sufficient representation of households across both rural and urban environments.

For each landscape area the relevant Census OAs were ordered by the strata: Government Office Region and urbanisation (i.e. urban or rural). Additionally they were ordered within the strata by Local Authority area in order to ensure that a geographic spread across England was achieved. For each strata a random start and sampling interval was taken and the OAs were selected using probabilityproportional-to-size (PPS) sampling based on the number of households in each OA. There were 180 different sampling points based on OAs, drawn from 160 different local authority areas in England. The sample was representative of urban, town and suburban OAs.

Table 1 reports on the sample sizes obtained and compares sample and population proportions from each landscape category. The majority of respondents (over 55\%) came from the Upland \& Upland Fringe and South East Mixed landscapes while less than 11\% came from the Chalk \& Limestone Mixed Landscape. Statistical tests (see Boatman et al., 2010) confirmed that the sample was representative according to the parameters used to stratify the population. 
Table 1 Sample frequency by landscape category

\begin{tabular}{llll}
\hline $\begin{array}{l}\text { LANDSCAPE } \\
\text { CATEGORY }\end{array}$ & $\begin{array}{l}\text { Sample } \\
\text { Frequency }\end{array}$ & $\begin{array}{l}\text { Percentage in } \\
\text { Sample }\end{array}$ & $\begin{array}{l}\text { Percentage in } \\
\text { Population }\end{array}$ \\
\hline Chalk \& Limestone Mixed & 162 & 10.8 & 10.6 \\
Eastern Arable & 252 & 16.8 & 16.7 \\
South-East Mixed & 378 & 25.2 & 25.3 \\
Western Mixed & 254 & 16.9 & 16.9 \\
Upland and Upland Fringe & 454 & 30.3 & 30.5 \\
\hline TOTAL & 1500 & 100 & 100 \\
\hline
\end{tabular}

Respondents were thoroughly briefed about the five landscape types. This included giving them information about their distribution, character and the environmental and landscape benefits likely to be generated by achieving the target level of participation in both HLS and ELS. Before undertaking the CE, all respondents were shown a series of statements about ES benefits and asked to identify the one with which they most agreed (see Table 2). This exercise revealed that $15 \%$ of respondents agreed with the statement that they would get similar benefits from ES across all five landscape types. As a cost-saving measure these 227 respondents were excluded from the subsequent $\mathrm{CE}$ exercise on the assumption that their preferences were now known. The majority of respondents $(58 \%)$ agreed that the benefits they would get from ES would vary across the five landscape types, while the remaining respondents were unsure whether they would get similar or different benefits from the scheme across the landscape types. All respondents in these last two groups were asked to participate in the CE.

Table 2 Respondents' views on how they will benefit from ES

\begin{tabular}{lll}
\hline STATEMENT & $\begin{array}{l}\text { Number who } \\
\text { agreed with the } \\
\text { statement }\end{array}$ & Percent \\
\hline $\begin{array}{l}\text { I will get similar benefits from the scheme } \\
\text { across all landscape types }\end{array}$ & 227 & 15.1 \\
$\begin{array}{l}\text { The benefits that I will get from the scheme } \\
\text { will vary across the five landscape types }\end{array}$ & 876 & 58.4 \\
$\begin{array}{l}\text { I'm not sure whether I will get similar or } \\
\text { different benefits from the scheme across the } \\
\text { five landscape types }\end{array}$ & 320 & 21.3 \\
Missing/Don't know & 77 & 5.1 \\
\hline
\end{tabular}

After completing the CEs, respondents were asked how easy they found the task. Over half of respondents agreed that the task had been relatively easy, though nearly a quarter suggested that the task had been difficult (see Boatman et al., 2010 for more 
details). This distribution of responses is not unexpected as one of the reasons for conducting CEs is to ask respondents to make non-trivial choices between options that require them to trade off one desirable attribute against another in a way that reveals their relative preferences. It could be argued that those respondents who found the choice experiment most challenging should be omitted from the analysis; however, there is no evidence to suggest that their responses are any less valid than those who found the choice task easy (indeed it is possible that the difficulty in selection reflected the need to make hard choices rather than the complexity of the task).

Respondents were also asked to reflect on their choices and the benefits that they received from ES. A clear majority of respondents (73\%) agreed that they would benefit most from the scheme improving the environment in the landscapes near to where they live (see Boatman et al., 2010). Similarly, nearly three quarters agreed that they would benefit most from the scheme in areas that they visited for recreation (see Boatman et al., 2010). These preferences for ES benefits in specific landscapes will be investigated further when modelling the choice experiment data.

Nearly $7 \%$ of respondents who undertook the questionnaire agreed strongly with a statement suggesting that they did not have enough information on the scheme to know where and how they will benefit from it (see Boatman et al., 2010). Analysis of choice responses from this latter group showed their preferences to be at significant variance to the remainder of the sample, perhaps reflecting some of the confusion that these respondents may have felt when making their choices. As a result it was decided to omit the responses of these 103 individuals from all subsequent analyses on the basis that their responses are probably least likely to accurately reflect preferences for scheme benefits across landscapes. This left 4720 usable responses.

\section{Results}

Responses reported in Table 2 indicated that most respondents do not have homogenous preferences for ES benefits across the five landscapes. This is consistent with the results of Brouwer et al. (2010), who suggested that where a respondent lives might influence preferences for spatially-specific environmental benefits.

First, an important issue in the empirical application of latent class models (LCM) is the number of segments to be used in the analysis. Formal statistical criteria for determining the number of segments, however, do not yet exist. As a guide to the selection of the optimal model, a number of authors have suggested the use information theoretic criteria tempered by the analyst's own judgment (e.g. Boxall and Adamowicz, 2002; Scarpa and Thiene, 2005). This paper uses the Akaike Information Criteria (AIC) as a guide to the selection of the optimal model tempered by our judgement of the interpretability of the model and significance of parameter estimates. Therefore it was decided that a four segment model is the preferred specification. Maximum likelihood parameter estimates of the four segment model are reported in Table 3. It is noteworthy the model fit substantially improved from an initial one segment (MNL) model (not reported) to the four segment model (pseudo$R^{2}$ increases from $25 \%$ to $31 \%$ ); this information supports the existence of heterogeneity in the data and suggest existence of latent segments. 
Table 3 Baseline four-segment latent class model

\begin{tabular}{lllll}
\hline & $\begin{array}{l}\text { Segment 1: } \\
33.99 \%\end{array}$ & $\begin{array}{l}\text { Segment 2: } \\
44.87 \%\end{array}$ & $\begin{array}{l}\text { Segment 3: } \\
13.28 \%\end{array}$ & $\begin{array}{l}\text { Segment 4: } \\
7.85 \%\end{array}$ \\
\hline $\begin{array}{l}\text { Landscape in which } \\
\text { ES is operational }\end{array}$ & $\begin{array}{l}\text { Coefficient } \\
(\mathrm{t}-\mathrm{value})\end{array}$ & $\begin{array}{l}\text { Coefficient } \\
(\mathrm{t}-\mathrm{value})\end{array}$ & $\begin{array}{l}\text { Coefficient } \\
(\mathrm{t}-\mathrm{value})\end{array}$ & $\begin{array}{l}\text { Coefficient } \\
(\mathrm{t}-\mathrm{value})\end{array}$ \\
\hline $\begin{array}{l}\text { Chalk and limestone } \\
\text { mixed }\end{array}$ & $1.592^{\mathrm{a}}$ & $0.523^{\mathrm{b}}$ & $0.330^{\mathrm{c}}$ & $-0.514^{\mathrm{d}}$ \\
Eastern Arable & $(8.22)$ & $(9.81)$ & $(2.99)$ & $(3.36)$ \\
& $1.212^{\mathrm{a}}$ & $1.200^{\mathrm{a}}$ & $-0.764^{\mathrm{c}}$ & $-0.158^{\mathrm{b}}$ \\
South-East Mixed & $(6.71)$ & $(21.90)$ & $(5.66)$ & $(0.99)$ \\
& $1.679^{\mathrm{a}}$ & $1.046^{\mathrm{b}}$ & $0.484^{\mathrm{c}}$ & $-0.952^{\mathrm{d}}$ \\
Western Mixed & $(9.29)$ & $(19.97)$ & $(4.43)$ & $(6.24)$ \\
& $1.812^{\mathrm{a}}$ & $0.604^{\mathrm{c}}$ & $1.427^{\mathrm{b}}$ & $-1.257^{\mathrm{d}}$ \\
Upland and Upland & $(8.89)$ & $(11.27)$ & $(10.92)$ & $(7.93)$ \\
Fringe & $1.790^{\mathrm{b}}$ & $0.355^{\mathrm{c}}$ & $1.908^{\mathrm{a}}$ & $-0.121^{\mathrm{d}}$ \\
\hline
\end{tabular}

${ }^{a, b, c}$ Differences in the superscripts denote significant differences, at $5 \%$ level or better, in coefficients across segments.

The results show that there is considerable heterogeneity in preferences for ES benefits across segments as indicated by the differences in the magnitude, significance and signs of parameter estimates. In segment one, respondents had broadly similar preferences across four landscapes with a lower preference for Eastern Arable. Respondents in segments two and three had mostly positive preferences for the benefits of ES in all five landscapes but in segment two the strongest preferences were for the predominantly lowland landscapes in Eastern Arable and South-East Mixed, while in segment three the stronger preferences were linked to the hillier landscapes of Upland \& Upland Fringe and Western Mixed landscapes, with a negative preference for Eastern Arable.

In the small fourth segment, respondents had a negative preference for ES benefits in three landscapes and were indifferent to ES benefits in Upland Fringe and Eastern Arable. A negative and indifferent segment of similar magnitude was observed in each of the two, three and five segment models that were also estimated (but are not reported here), suggesting that there is a small but significant segment of respondents (between seven and nine percent) making a set of choices that taken together reveal no distinct positive preferences for ES benefits in any landscape, but rather a negative preference for them in some landscapes. Such a result might be observed if an individual's preferences for some landscapes were articulated in an inconsistent fashion (e.g. for a single respondent of this type some choices might indicate a positive preference for ES benefits in one landscape compared to others, while other choices might contradict that observation). 
Table 4: Predicted segment membership by home landscape of respondent

\begin{tabular}{llllll}
\hline \multicolumn{7}{c}{ Segment membership } \\
& Segment 1 & Segment 2 & Segment 3 & Segment 4 & Total \\
\hline Chalk \& Limestone Mixed & $11.1 \%$ & $11.7 \%$ & $5.9 \%$ & $4.5 \%$ & $10.4 \%$ \\
Eastern Arable & $17.6 \%$ & $18.4 \%$ & $11.9 \%$ & $11.2 \%$ & $16.9 \%$ \\
South-East Mixed & $21.1 \%$ & $29.5 \%$ & $23.8 \%$ & $36.0 \%$ & $26.1 \%$ \\
Western Mixed & $35.6 \%$ & $25.6 \%$ & $35.6 \%$ & $33.7 \%$ & $31.1 \%$ \\
Upland and Upland Fringe & $14.6 \%$ & $14.8 \%$ & $22.8 \%$ & $14.6 \%$ & $15.4 \%$ \\
\hline
\end{tabular}

Table 4 takes the analysis of the four-segment model a step further by reporting on predicted segment membership by the home landscape of the respondent. Casual inspection of Table 4 shows that, although respondents from some landscapes seem more or less likely to belong to certain segments, respondents living in each of the five landscapes are represented in all segments. A chi-squared test of whether or not the relationship between segment membership and home landscape is the same for each landscape type does, however, reveal a strongly significant link between respondents' home landscapes and the segments that they are predicted to be in, indicating that the probability of belonging to a particular segment is influenced by the landscape where a respondent lives. For example, respondents living in the Western Mixed landscape are the least well represented group in segment two (where members have lower preferences for this landscape than in Segments 1 and 3), while respondents living in the Eastern Arable landscape make up higher proportions of segments 1 and 2 (where the greatest preferences for this landscape are found). Similarly, the segment with the highest proportion of respondents from the Upland and Upland Fringe landscape is Segment 3, members of which have the highest preferences for that landscape.

Table 5 Mean distance from respondents' homes to landscapes by segment

\begin{tabular}{llllll}
\hline & Segment 1 & Segment 2 & Segment 3 & Segment 4 & Total \\
\hline Chalk \& & 37.72 & 26.11 & 37.66 & 37.23 & 30.20 \\
Limestone Mixed & $(34.54)^{\mathrm{a}}$ & $(28.56)$ & $(33.96)$ & $(38.64)$ & $(32.58)$ \\
South East Mixed & 52.90 & 48.22 & 55.96 & 61.58 & 51.75 \\
& $(49.50)$ & $(46.62)$ & $(57.23)$ & $(71.16)$ & $(50.89)$ \\
Eastern arable & 132.26 & 104.42 & 130.19 & 107.29 & 118.34 \\
& $(113.89)$ & $(107.18)$ & $(110.90)$ & $(108.65)$ & $(111.10)$ \\
Western Mixed & 35.63 & 45.65 & 38.19 & 32.11 & 39.92 \\
& $(39.62)$ & $(43.58)$ & $(41.46)$ & $(34.48)$ & $(41.47)$ \\
Upland \& & 66.60 & 86.45 & 68.33 & 73.97 & 75.82 \\
Upland Fringe & $(71.17)$ & $(77.91)$ & $(76.38)$ & $(70.98)$ & $(75.07)$ \\
\hline
\end{tabular}

${ }^{\mathrm{a}}$ Standard deviations in parentheses 
Table 5 reports the mean distance (as measured by the shortest straight line to the edge of a relevant landscape polygon) between where respondents live and the five landscape types for each of the four segments. Inspection of Table 5 reveals that in each segment respondents on average live nearest to the Chalk \& Limestone Mixed and Western Mixed landscapes and furthest away from the Eastern Arable landscape. A series of one-way ANOVA F-tests was conducted to investigate the relationship between distance from respondents' homes to the five landscapes and respondents' segment membership. This revealed strong significant relationships for all landscape types except Eastern Arable, generally the most distant (and possibly least accessible) landscape type (see Boatman et al., 2010). Therefore, the distance between respondents' homes and the four most commonly proximate landscape types is a significant determinant of segment membership.

\section{Conclusions}

In his review of the potential of agri-environment schemes (AESs) to deliver biodiversity gains and ecosystem services, Whittingham (2011) concludes that there is evidence to suggest that spatially targeted options can yield substantial biodiversity benefits. Such benefits depend upon the provision of careful management advice and the cooperation of farmers (Whittingham, 2011). The link between spatially targeted AES options and biodiversity outcomes suggests that the benefits of agri-environment policy are likely to vary over space to reflect the distribution of important habitats and sources of other ecosystems services. This observation, when coupled with evidence from previous studies that individual preferences for both landscapes and environmental goods are likely to be heterogeneous, suggests that it is likely that the general public would value the benefits of an AES differently depending on the landscapes where they are generated.

This study investigated individual preferences for the benefits associated with ES across five broad landscape types. A choice experiment approach was used to derive data on relative preferences for ES benefits across landscape types and this data was analysed using a latent class approach that enabled the study to test the hypothesis of homogenous preferences for the benefits of ES across the sample.

Like the earlier work of Brouwer et al. (2010), the results of the latent class analysis strongly suggest spatial heterogeneity of preferences for environmental benefits within the population from which the sample drawn. They also reveal the existence of segments within the population that exhibit more homogenous preferences. In one segment respondents have broadly similar preferences for four of the five landscapes, while respondents in two further segments exhibit stronger preferences for ES benefits in landscapes that are predominantly upland or lowland respectively. Additional analysis reveals that the distance between respondents' homes and the four most commonly proximate landscape types is a significant determinant of segment membership.

This all suggests that while that the majority of the general public have positive and significant preferences for ES to generate environmental benefits across all of England, most people still have a preference for benefits to be delivered in those areas 
closest and most accessible to where they live. This in turn suggests that while a significant proportion of the benefits associated with the scheme are use benefits, a proportion are likely to be non-use benefits probably linked to biodiversity conservation in areas respondents are unlikely to visit.

Considering the segments, some broad conclusions can be drawn about the heterogeneity of preferences. Segment 4 reveals a small but significant group of people (around 8\% of the sample) who are either indifferent to or have a negative preference for ES benefits across the different landscape types (perhaps being supporters of more productive agricultural land use). The remaining segments have unambiguously positive preferences for ES benefits. In segment 1 (covering around a third of the sample), respondents had a lower preference for Eastern Arable but with similar preferences for the remaining landscapes. Respondents in segment two (covering around $44 \%$ of the sample) had stronger preferences for the predominantly lowland landscapes (including eastern arable) while in segment three (around 13\% of the sample) the stronger preferences were linked to hillier landscapes.

By demonstrating heterogeneity of preferences for the benefits of ES, and in particular higher preferences for ES benefits in the landscapes nearest to where respondents live, these findings provide support to the proposition that AES funding should be further targeted at specific spatial areas. Existing targeting largely reflects the potential for an area to deliver biodiversity benefits and ecosystem services. In order to maximize the level of environmental benefits that ES can provide to the public, the results of this study could suggest that there is some merit to increasing the funding available to land closest to areas of high population. Such targeted spending would reflect the observation that most respondents place a higher value on benefits that are generated closer to where they live, giving people a greater chance of encountering evidence of enhanced biodiversity or a better managed landscape. One important caveat to this approach would be the need to take into account the possibility that the cost of delivering equivalent levels of environmental improvement may differ across landscapes, suggesting that spatially disaggregated information on the cost of delivering biodiversity conservation is required before any substantive changes to targeted spending are made.

Where public funding is used to deliver environmental benefits, it is common for some element of targeting to be used to determine where those funds are spent. Based on the results reported in this paper, we argue that it is inappropriate to base a targeting strategy solely on the delivery of scientific priorities. Rather, we suggest a strategy that combines scientific judgment with data on any spatial variations in the benefits and costs of the scheme. Some commentators may go even further and suggest that policy prescriptions should also take account of the potential trade-offs that individuals might make between their preferences for biodiversity and landscape and the impact of policies on other social issues related to farming (e.g. agrienvironment schemes may have an impact on the production of local food and therefore on 'food miles'). 
Our understanding of how individuals value AES benefits and how this might be reflected in the design of schemes, would be improved by further research into the extent to which preferences are associated with the landscape itself (e.g. due to proximity to a particular landscape type or to aesthetic preferences for its physical appearance), or with the range of goods and services (non-market or otherwise) produced by different landscape types. Such research could be extended across a less general landscape typology than that used here and could usefully reflect the visual and environmental characteristics of the landscape.

\section{References}

Adamowicz, W. L., Boxall, P. and Louviere, J. 'Stated preference approaches for measuring passive use values: Choice experiments and contingent valuation', American Journal of Agricultural Economics, Vol. 80 Issue 1, (1998) pp. 64-75.

Bateman, I.J., Mace, G.M., Fezzi, C., Atkinson, G. and Turner, R.K., 2011 Economic Analysis for Ecosystem Service Assessments. Environmental and Resource Economics 48, 177-218.

Birol, E., Karousakis, K., Koundouri, P., 2006. Using a choice experiment to account for preference heterogeneity in wetland attributes: The case of Cheimaditida wetland in Greece. Ecological Economics 60, 145-156.

Bishop, I.D. and Hull, R.B. 1991. Integrating technologies for visual resource management. Journal of Environmental management, 32, 295-312.

Boatman, N., Willis, K.G. Garrod, G.D., Powe, N.A., 2010. Estimating the wildlife and landscape benefits of Environmental Stewardship. Prepared for DEFRA by Food and Environment Research Agency and Newcastle University. Available at: http://archive.defra.gov.uk/evidence/economics/foodfarm/reports/documents/estimati ngthewildlife.pdf (Last accessed 22/6/11)

Boxall, P. C., Adamowicz, W.L., 2002. Understanding heterogeneous preferences in random utility models: a latent class approach. Environmental and Resource Economics 23, 421-446.

Brouwer, R., Martin-Ortega, J., Berbel, J., 2010. Spatial preference heterogeneity: A Choice Experiment. Land Economics 86, 552-568.

Campbell, D., 2007. Willingness to pay for rural landscape improvements: Combining mixed logit and random-effects models. Journal of Agricultural Economics 58, 467-483.

Daniel, T.C. and Meitner, M. 2001. Representational validity of landscape visualisations: the effects of graphical realism on perceived scenic beauty of forest vistas. Journal of Environmental Psychology 21, 61-72. 
Davey, C.M., Vickery, J.A., Boatman, N., Chamberlain, D., Parry, H., Siriwardena, G.M., 2010. Regional variation in the efficacy of Entry Level Stewardship in England. Agriculture, Ecosystems \& Environment 139, 121-128.

DEFRA and Natural England, 2008. Environmental Stewardship review of progress. DEFRA, London. Available at: http://collections.europarchive.org/tna/20081027092120/http://defra.gov.uk/erdp/sche mes/es/es-report.pdf (Last accessed 15/1/11).

DEFRA, 2007. A Rural/Urban Classification of Parliamentary Constituencies of England and Wales 2007. DEFRA, London. Available at:

http://archive.defra.gov.uk/evidence/statistics/rural/documents/rural-defn/parliaconstituencies-classification.pdf (Last Accessed: 21/6/11).

Dramstad, W.E., Tveit, S.M., Fjellstad, W.J., Fry, G.L.A., 2006. Relationships between visual landscape preferences and map-based indicators of landscape structure. Landscape and Urban Planning 78, 465-474.

Espinosa-Goded, M., Barreilo-Hurle, J., Ruto, E., 2010. What do farmers want from agri-environmental scheme design? A choice experiment approach. Journal of Agricultural Economics, Vol. 61 Issue 2, (2010) pp. 259-273.

Ewald, J.A., Aebischer, N.J., Richardson, S.M., Grice, P.V., Cooke, A.I., 2010. The effect of agri-environment schemes on grey partridges at the farm level in England. Agriculture, Ecosystems and Environment 138: 55-63.

Field, R.H., Morris, A.J., Grice' P.V., Cooke A., 2011. The provision of winter bird food by the English Environmental Stewardship Scheme. Ibis 153, 14-26.

Garrod, G.D., Scarpa, R., Willis K.G., 2002. Estimating the benefits of traffic calming on through routes: a choice experiment approach. Journal of Transport Economics and Policy 36, 211-231.

Glenk, K., 2011. Using local knowledge to model asymmetric preference formation in willingness to pay for environmental services. Journal of Environmental Management 92, 531-541.

González, M., León, C., 2003. Consumption, process and multiple valuation of landscape attributes. Ecological Economics 45, 159-169.

Greene, W.H., Hensher, D.A., 2003. A latent class model for discrete choice analysis, contrasts with mixed logit. Transportation Research Part B-Methodological 37, 681698.

Hanley, N., Colombo, S., Johns, H., Mason, P., 2007. The reform of support mechanisms for upland farming: Paying for public goods in the severely disadvantaged areas of England. Journal of Agricultural Economics 58, 433-453. 
Hanley, N., Ready, R., Colombo, S., Watson, F., Stewart, M., Bergmann, E.A. (2009). The impacts of knowledge of the past on preferences for future landscape change. Journal of Environmental Management 90, 1404-1412.

Hausman, J. and McFadden, D., 1984. Specification tests for the multinomial logit model. Econometrica 52:5, 1219-1240.

Hunziker, M. (1995). The spontaneous reafforestation in abandoned agricultural lands: perception and aesthetic assessment by locals and tourists. Landscape and Urban Planning 31, 399-410.

Hynes, S., Campbell, D. Howley, P., 2011. A holistic vs. an attribute-based approach to agri-environmental policy valuation: do welfare estimates differ? Journal of Agricultural Economics 62, 305-329.

Karjalainen, E. and Tyrvainen, L. 2002. Visualisation in forest landscape preference research: a Finnish perspective. Landscape and Urban Planning, 59, 13-28.

Kearney, A.R., Bradley, G.A., Petrich, C.H., Kaplan, R., Kaplan, S., SimpsonColebank, D., 2008. Public perception as support for scenic quality regulation in a nationally treasured landscape. Landscape and Urban Planning 87, 117-124.

Kleijn, D., Berendse, F., Smit, R., Gilissen, N., Smit, J., Brak, B., and Groeneveld, R. 2004. Ecological Effectiveness of Agri-Environment Schemes in Different Agricultural Landscapes in The Netherlands. Conservation Biology, 18, 775-786.

Lokocz, E., Ryan R.L, Sadler A.J., 2011. Motivations for land protection and stewardship: Exploring place attachment and rural landscape character in Massachusetts. Landscape and Urban Planning 99, 65-76.

McFadden, D., 1974. Conditional logit analysis of qualitative choice behaviour, in: Zarembka, P. E. (Ed.), Frontiers in Econometrics. Academic Press, New York.

McFadden, D., Train, K., 2000. Mixed MNL models for discrete response. Journal of Applied Econometrics 15, 447-470.

Meitner, M.J. 2004. Scenic beauty of river views in the Grand Canyon: relating perpetual judgements to locations. Landscape and Urban Planning 68, 3-13.

Morey, E., Thiene M., de Salvo M., Signorello, G., 2008. Using attitudinal data to identify latent classes that vary in their preferences for landscape preservation. Ecological Economics 68, 536-546.

Natural England, 2011a. Look After Your Land with Environmental Stewardship. Natural England, London. Available at: http://naturalengland.etraderstores.com/NaturalEnglandShop/NE124. (Last accessed 21/6/11). 
Natural England, 2011b. Assessing and Responding to Climate Change Risks in Natural England's Objectives. Report to the Secretary of State for Environment, Food and Rural Affairs. Natural England, London. Available at:

http://archive.defra.gov.uk/environment/climate/documents/interim2/natural-englandclimate-risk-report-1010.pdf (Last accessed 21/6/11).

Park, J.J., Jorgensen, A., Swanwick, C., Selman, P., 2008. Perceived landscape impacts of mobile telecommunications development in the Peak District National Park, England. Journal of Environmental Planning and Management 51, 679-699.

Pruckner, G. J., 1995. Agricultural landscape cultivation in Austria: An application of the CVM. European Review of Agricultural Economics 22, 173-190.

Purcell, A.T., Lamb, R.J., Peron, E.M., Falchero, S., 1994. Preference or preferences for landscape. Journal of Environmental Psychology 14, 195-209.

Quillerou, E., Fraser, R. and Fraser, I., 2011. Farmer compensation and its consequences for environmental benefit provision in the Higher Level Stewardship Scheme. Journal of Agricultural Economics 62, 330-339.

Ruto, E., Garrod, G.D., 2009. Investigating farmers' preferences for the design of agri-environment schemes: a choice experiment approach. Journal of Environmental Planning and Management 52, 631-647.

Ruto, E., Garrod, G.D., Scarpa, R., 2008. Valuing animal genetic resources: a choice modelling application to indigenous cattle in Kenya. Agricultural Economics 38, 8998 .

Sayadi, S., Gonlazez Roa, M.C., Requena J.C., 2005. Ranking versus scale rating in conjoint analysis: evaluating landscapes in mountainous regions in southeastern Spain. Ecological Economics 55, 539-530.

Scarpa, R., Thiene, M., 2005. Destination choice models for rock climbing in the Northeastern Alps: A latent class approach based on intensity of preferences. Land Economics 81, 426-444.

Sevenant, M., Antrop, M., 2010. The use of latent classes to identify individual differences in the importance of landscape dimensions for aesthetic preference. Land Use Policy 27, 827-842.

Swanwick, C., Hanley, N., Termansen, M., 2007. Scoping study on agricultural landscape valuation. Final report to DEFRA. Department of Landscape, University of Sheffield.

Train, K., 2003. Discrete Choice Models with simulation. Cambridge University Press, Cambridge.

Wedel, M., Kamukura, W., 2000. Market Segmentation: Conceptual Methodological Foundations. Kluwer Academic Publishers, Boston. 
Whittingham, M.J., 2011. The future of agri-environment schemes: biodiversity gains and ecosystem service delivery? Journal of Applied Ecology 48, 509-513.

Willis, K.G. and Garrod, G.D. 1992. Assessing the Value of Future Landscapes. Landscape and Urban Planning 23, 17-32.

Willis, K.G., Garrod, G.D., Saunders, C.M., 1995. Benefits of Environmentally Sensitive Area Policy in England: A Contingent Valuation Assessment. Journal of Environmental Management 44, 105-125.

\section{Appendix A: Descriptions of the landscape types}

\section{Chalk \& Limestone Mixed Farming}

In general the landscapes are open with rolling hills and relatively low amounts of woodland. They are predominantly rural, with only $6 \%$ of land classified as urban. On average, around two thirds of the agricultural land is occupied by farms growing mainly crops, the remainder being split between dairy farms, farms with sheep and beef cattle, and mixed farms with both crops and livestock. Farms specialising in pigs, poultry and horticulture cover only a very small proportion of the land area. Cropping is mainly of cereals and other 'combinable' crops such as oilseed rape and peas, with few root crops (potatoes, sugar beet etc.) in most areas.

\section{Eastern Arable}

The landscapes are generally flat and low lying, and in some areas such as the Fens and Humberhead levels, occupy former wetlands. Here drainage ditches or dykes often separate the fields rather than hedges. The soils are often of good quality and high yielding, and for this reason, over $80 \%$ of the agricultural area is devoted to farms dominated by cropping, with the widest range of different crops being grown in these areas, though the area of horticultural crops is limited. Because the land has a high value for growing crops, the area of woodland is limited, and there are few livestock farms. The landscapes remain predominantly rural, with only around $8 \%$ of the area classified as urban.

\section{South East Mixed (wooded)}

Soil types are predominantly sand or clay. A high proportion (over 20\%) of the land is urban or suburban. There is also a high proportion of woodland relative to the other landscape types. The agriculture is varied and diverse, with around $45 \%$ of the agricultural area taken up by crop-dominated farms, $20 \%$ by livestock farms, and $9 \%$ by mixed farms. Much of the landscape is a patchwork of farmland, woodland and settlements, with fields often small and surrounded by hedgerows. This landscape type also has the highest area of land devoted to horticultural farms (4\%), and orchards are common in Kent. Nineteen percent of the area is taken up by 'other' farm types, most of which are smallholdings or other small non-commercial or hobby farms. 


\section{Upland and Upland Fringe}

The poor soils, uneven topography and cool wet climate mean that upland areas are generally unsuited to arable cropping, so farming is predominantly pastoral. Over $60 \%$ of the area is devoted to grazing livestock, with a further $9 \%$ taken up by mixed farms. Crop-dominated farms cover only around $13 \%$ of the area. Landscapes are generally open on the hills, with vegetation composed of heather, bracken and rough grasses. Fields of improved grass ('in-bye' land) are found on the lower slopes and valleys, divided predominantly by stone walls. Broadleaved or deciduous woodland is scarce on the open moors, but is more frequent in steep-sided valleys. In some areas there are also have large blocks of coniferous forestry plantations. Urbanised areas cover around 5\% of the landscape type, most of this being accounted for by the industrial conurbations of West Yorkshire and Derbyshire. Away from these areas, the uplands are sparsely populated.

\section{Western Mixed}

Generally low-lying, these are typically a pastoral landscapes, though around $13 \%$ of the land area is urban, including the conurbations centred around Birmingham, Manchester and Liverpool. Fields are divided by hedges, often containing mature trees. Much of the land is devoted to livestock enterprises, though over a third of the area is still taken up with farms classified as arable or general cropping, and a further $10 \%$ classified as mixed. This landscape type has more dairy farming than any other, with nearly $20 \%$ of the land area devoted to dairy farms. A further $17 \%$ of the land area is taken up by lowland grazing livestock (cattle and sheep) farms. Hops and orchards are found in the Herefordshire area. 


\section{Appendix B: Distribution of landscape types}

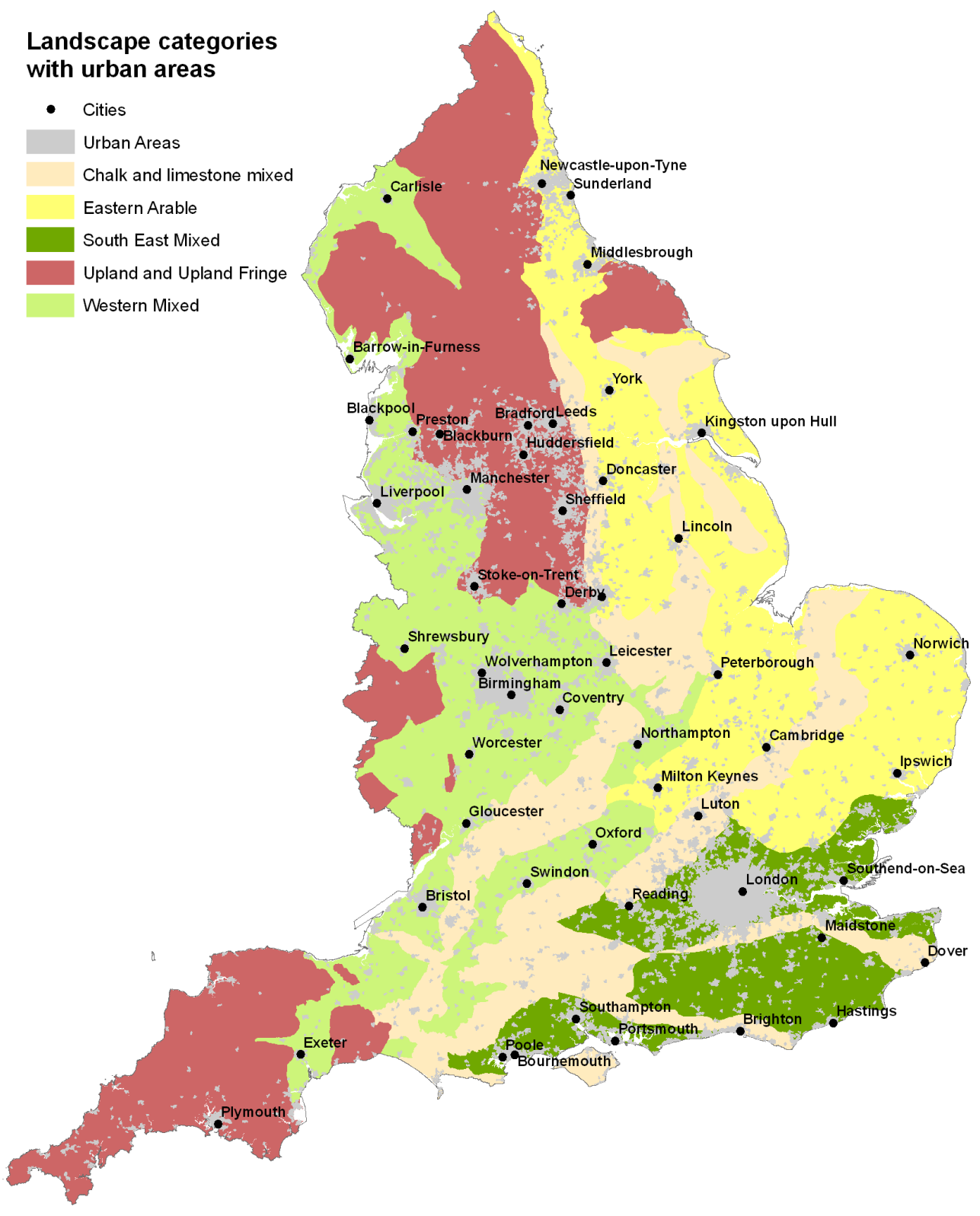

